\title{
Real-World Experience of Treating Pediatric Chronic Myeloid Leukemia: Retrospective Study from a Cancer Center in Southern India
}

\author{
Sivasree Kesana ${ }^{1}$ Venkatraman Radhakrishnan ${ }^{10}$ Jayachandran Perumal Kalaiyarasi ${ }^{10}$ \\ Nikita Mehra1@ Gangothri Selvarajan ${ }^{1}$ Parathan Karunakaran ${ }^{1}$ Krishnarathinam Kannan ${ }^{1}$ \\ Manikandan Dhanushkodi ${ }^{1}$ Shirley Sundersingh ${ }^{2}$ Samson Mani ${ }^{3}$ Trivadi S. Ganesan ${ }^{10}$ \\ Tenali Gnana Sagar ${ }^{1}$
}

1 Department of Medical Oncology, Cancer Institute (WIA), Adyar, Chennai, Tamil Nadu, India

2 Oncopathology, Cancer Institute (WIA), Adyar, Chennai, Tamil Nadu, India

${ }^{3}$ Molecular Oncology, Cancer Institute (WIA), Adyar, Chennai, Tamil Nadu, India

Ind J Med Paediatr Oncol 2021;42:561-568.

\begin{abstract}
Address for correspondence Venkatraman Radhakrishnan, MD, DM, Professor, Medical and Pediatric Oncology, Cancer Institute (WIA), Adyar, Chennai, Tamil Nadu 600020, India (e-mail: venkymd@gmail.com).
\end{abstract}

\begin{abstract}
Keywords

- pediatric

- chronic myeloid leukemia

- imatinib

- responses

- survival outcomes

Introduction Chronic myeloid leukemia (CML) is rare in children and constitutes $2 \%$ of all leukemia. We present our institute experience in treating pediatric CML for 20 years. Objectives There is a paucity of data on pediatric CML from India, hence we would like to present treatment responses and survival rates in our pediatric population treated with tyrosine kinase inhibitors at our center.

Materials and Methods Patients aged less than 18 years, diagnosed with CML from 2000 to 2019, and treated with imatinib were analyzed retrospectively considering demographic features, treatment characteristics, and survival outcomes. Descriptive analysis was done for the baseline characteristics. Event-free survival (EFS) and overall survival (OS) were calculated using the Kaplan-Meier method and the factors were compared using the log-rank test.

Results During the study period, 95 patients were diagnosed with CML of which 54 (56.8\%) were males. The most common stage at presentation was the chronic phase (CP) with $84(88.4 \%)$ patients followed by accelerated phase (AP) and blast crisis (BC) with $6(6.3 \%)$ and 5 (5.3\%) patients respectively. The median duration of follow-up for all patients was 98 months. EFS and OS at 8 years for patients with CML-CP were $43.1 \%$ and $80.4 \%$ respectively. Complete hematological response, complete cytogenetic response, and major molecular response was documented in 91 (95.7\%), 73 (76.8\%), and 63 (66.3\%) patients respectively.

Conclusion Outcomes in pediatric CML are comparable to that of adults. Imatinib is well tolerated in children.
\end{abstract}

DOI https://doi.org/ 10.1055/s-0041-1740951. ISSN 0971-5851. (c) 2021. Indian Society of Medical and Paediatric Oncology. All rights reserved.

This is an open access article published by Thieme under the terms of the Creative Commons Attribution-NonDerivative-NonCommercial-License, permitting copying and reproduction so long as the original work is given appropriate credit. Contents may not be used for commercial purposes, or adapted, remixed, transformed or built upon. (https://creativecommons.org/ licenses/by-nc-nd/4.0/)

Thieme Medical and Scientific Publishers Pvt. Ltd., A-12, 2nd Floor, Sector 2, Noida-201301 UP, India 


\section{Introduction}

Chronic myeloid leukemia (CML) is rare in children and constitutes $2 \%$ of all leukemia in pediatric age group younger than 15 years and $9 \%$ in adolescents aged between 15 and 19 years. ${ }^{1-3}$ Management of CML in children is challenging due to the lifelong treatment with tyrosine kinase inhibitors (TKIs) like imatinib and long-term adverse effects of TKI., ${ }^{2,4}$ These challenges are amplified in resource-challenged settings in low/middle-income countries due to delayed presentation, poor compliance to treatment, treatment abandonment, and access to drugs.

The use of hematopoietic stem cell transplantation (HSCT) to treat children in the chronic phase (CP) CML is no longer recommended with the advent of TKI. ${ }^{2,5}$ Imatinib has been the backbone for treating CML in children and recent evidence suggests that second-generation TKIs like dasatinib and nilotinib are safe and efficacious in children with CML. ${ }^{5,6}$

Our study adds to the literature from India on pediatric CML by providing details on the clinical profile, management, and outcomes of pediatric CML treated at our center.

\section{Materials and Methods}

\section{Inclusion Criteria}

Retrospective data on 95 consecutive patients aged less than 18 years and diagnosed as Philadelphia $(\mathrm{Ph})$ chromosomepositive CML at our hospital from January 2000 to December 2019 treated with TKI (imatinib) were analyzed.

\section{Exclusion Criteria}

CML patients aged more than 18 years and those who did not receive TKIs were excluded.

Baseline characteristics and other clinico-pathological features were extracted from the patient records. The procedures followed were in accordance with the ethical standards of the responsible committee on human experimentation (institutional) and with the Helsinki Declaration of 1964, as revised in 2013. This being a retrospective study, informed patient consent was waivered and approved by the hospital ethics committee (Institutional Ethics Committee, Cancer Institute (WIA), Adyar, Chennai; Accreditation number: EC-CT-2020-0141; Reference Number IEC/2020/Oct 01) on October 3, 2020.

The diagnosis of CML was established by clinical examination supported by hemogram, peripheral smear, bone marrow aspiration, and demonstration of the Ph chromosome either by conventional cytogenetics or fluorescent in situ hybridization (FISH). ${ }^{7}$ Confirmation of the presence of breakpoint cluster region-Abelson (BCR-ABL) fusion gene transcript was done by the reverse transcriptase polymerase chain reaction (RT-PCR) method. ${ }^{8}$

Accelerated phase (AP) was defined by any of the following features: basophils $\geq 20 \%$; blasts 10 to $19 \%$ in peripheral blood or bone marrow; persistent thrombocytopenia $\left(<100 \times 10^{9} / \mathrm{L}\right)$ unrelated to therapy or persistent thrombocytosis $\left(>1,000 \times 10^{9} / \mathrm{L}\right)$ unresponsive to therapy; increasing total white blood cell (WBC) count and increasing spleen size unresponsive to therapy; megakaryocytic proliferation in sizable sheets and clusters associated with marked reticulin or collagen fibrosis and/or severe granulocytic dysplasia; and cytogenetic evolution. ${ }^{9}$ Blast crisis (BC) was defined as blasts $\geq 20 \%$ in blood or bone marrow, large foci or clusters of blasts in bone marrow biopsy, or extra-medullary blast proliferation. All other patients who did not meet the criteria for AP or $\mathrm{BC}$ and blasts $<10 \%$ in peripheral blood or bone marrow were considered as $\mathrm{CP}^{9}{ }^{9}$

In children weighing $<40 \mathrm{~kg}$, imatinib was started at 260 to $300 \mathrm{mg} / \mathrm{m}^{2} .^{10}$ Children weighing $\geq 40 \mathrm{~kg}$ were started on imatinib $400 \mathrm{mg}$ daily. ${ }^{11}$ Dose escalation of imatinib was done if there was nonattainment or loss of response. Toxicity details were captured from the case files and were graded according to the Common Terminology Criteria for Adverse Events, version 4.03. Treatment was started after obtaining written informed consent for TKI from the parent/guardian.

Regular follow-ups included clinical examination and complete blood count. A complete hematologic response (CHR) was defined as $\mathrm{WBC}<10 \times 10^{9} / \mathrm{L}$, a platelet count $<450 \times 10^{9} / \mathrm{L}$, no palpable spleen, no immature cells, and basophils $<5 \%$ in peripheral blood smear. ${ }^{12,13}$ Cytogenetic response assessments have been replaced by real-time quantitative RT-PCR assessment at our center since 2013. A complete cytogenetic response (CCyR) was defined as the absence of the $\mathrm{Ph}$ chromosome in all analyzable metaphases on karyotyping. A BCR-ABL1/ABL1 transcript ratio $\leq 1 \%$ on the international scale by quantitative RT-PCR was considered equivalent to CCyR. ${ }^{12-15} \mathrm{~A}$ major molecular response (MMR) was defined as a BCR-ABL1/ABL1 transcript ratio $\leq$ $0.1 \%$ on the international scale by real-time quantitative RT$\mathrm{PCR}$, whereas a complete molecular response (CMR) was defined as an undetectable BCR-ABL1 transcript by two consecutive RT-PCRs with assay sensitivity of $10^{-4} \cdot \cdot^{13,16-18}$ Management of CML has evolved over the 20-year period, and this has reflected on patient care. Cytogenetic and molecular responses were assessed using FISH or quantitative PCR for BCR-ABL transcript levels from peripheral blood. Response assessment was not performed according to the guidelines due to financial constraints.

Imatinib was withheld for grade 3 or 4 toxicity and restarted at a lower dose and escalated based on tolerance. In patients who had progression of disease to AP or BC, the dose of imatinib was increased or palliative treatment with hydroxyurea initiated. More recently, with availability of second-generation TKIs these have been administered if there is no response to imatinib. Imatinib resistance mutational analysis (IRMA) was performed where feasible.

\section{Statistical Analysis}

Descriptive analysis was done for the baseline characteristics. An event in the study was defined as any loss of CHR or nonattainment at 3 months, CCyR at 6 months, and MMR at 12 months or progression to AP or BC or death due to any cause. Event-free survival (EFS) was calculated from the date of the start of therapy until the date of the first event. Overall survival (OS) was calculated from the date of the start of 
Table 1 Baseline clinical and laboratory parameters

\begin{tabular}{|l|l|}
\hline Characteristics & $\begin{array}{l}\text { Number of patients } \\
\text { (\%): total number }=95\end{array}$ \\
\hline Hemoglobin & \\
\hline$>10 \mathrm{gm} / \mathrm{dL}$ & $34(35.8)$ \\
\hline$<10 \mathrm{gm} / \mathrm{dL}$ & $61(64.2)$ \\
\hline Total leucocyte count $\left(\times 10^{9} / \mathrm{L}\right)$ & \\
\hline$<50$ & $11(11.6)$ \\
\hline $50-100$ & $13(13.7)$ \\
\hline $100-200$ & $42(44.2)$ \\
\hline$>200$ & $29(30.5)$ \\
\hline Platelet count $\left(\times 10^{9} / \mathrm{L}\right)$ & \\
\hline$<300$ & $22(23)$ \\
\hline$>300$ & $73(77)$ \\
\hline Spleen (below costal margin) & \\
\hline$<10 \mathrm{~cm}$ & $45(47.5)$ \\
\hline$>10 \mathrm{~cm}$ & $45(47.5)$ \\
\hline Missing data & $5(5)$ \\
\hline Sokal score & \\
\hline Low risk & $33(35)$ \\
\hline Intermediate risk & $41(43)$ \\
\hline High risk & $14(15)$ \\
\hline Missing data & $7(7)$ \\
\hline
\end{tabular}

therapy to the date of death or last follow-up. EFS and OS were analyzed using the Kaplan-Meier method and the factors were compared using the log-rank test. Statistical analysis was done using SPSS version 17.0 (SPSS Inc, IBM, Chicago, United States).

\section{Results}

During the study period, 95 patients were diagnosed with CML, of which 54 (56.8\%) were males and 41 (43.2\%) were females. The median age at presentation was 13 years. The most common stage at presentation was CP with $84(88.4 \%)$ patients followed by AP and BC with 6 (6.3\%) and 5 (5.3\%) respectively. Low- and intermediate-risk Sokal score (SS) was observed in 74 (78\%) patients. Four patients initially received hydroxyurea for 1 to 3 years followed by imatinib after the drug was made available in India from 2002 through an initiative called the Glivec International Patient Assistance Program. ${ }^{19}$ Baseline clinical and laboratory parameters are listed in -Table 1.

\section{Response}

CHR, CCyR, and MMR were documented in 91 (95.7\%), 73 (76.8\%), and 63 (66.3\%) patients respectively. Primary imatinib resistance was seen in three (3\%) patients. Results with imatinib treatment including attainment of CHR, CCyR, and MMR are provided in -Tables $\mathbf{2}$ and $\mathbf{3}$ (according to time-
Table 2 Results of imatinib treatment

\begin{tabular}{|c|c|}
\hline Parameter & Number (\%) \\
\hline Duration to attain $\mathrm{CHR}$ & $91(95.7)$ \\
\hline$<3$ months & $57(60)$ \\
\hline$>3$ months & $34(35.7)$ \\
\hline Nonattainment of CHR & $4(4.4)$ \\
\hline Duration to attain CCyR & $73(76.8)$ \\
\hline$<12$ months & $33(34.7)$ \\
\hline$>12$ months & $40(42.1)$ \\
\hline Nonattainment of CCyR & $22(23.1)$ \\
\hline Duration to attain MMR & $63(66.3)$ \\
\hline$<18$ months & $26(27.3)$ \\
\hline$>18$ months & 37 (38.9) \\
\hline Nonattainment of MMR & $32(33.6)$ \\
\hline \multicolumn{2}{|c|}{ Modification of imatinib dose } \\
\hline Escalated & $38(40)$ \\
\hline De-escalated & $4(4.2)$ \\
\hline Progressed on imatinib & $25(26.2)$ \\
\hline Lost to follow-up & $14(14.7)$ \\
\hline \multicolumn{2}{|l|}{ IRMA } \\
\hline Tested & $12(12.6)$ \\
\hline Positive & $5(5.2)$ \\
\hline T315I mutation & $3(3.1)$ \\
\hline E355G/E459L & $1(1.0)$ \\
\hline T277I & $1(1.0)$ \\
\hline
\end{tabular}

Abbreviations: CCyR, complete cytogenetic response; $\mathrm{CHR}$, complete hematological response; IRMA, imatinib resistance mutational analysis; MMR, major molecular response.

lines). Response assessment was not performed as per the guidelines due to logistic or noncompliance issues in 18 patients.

\section{Toxicity}

Most common imatinib-related side effects were polyarthralgia observed in 17 (17.8\%) patients, hypopigmentation of skin in 11 (11.5\%), hematological toxicity in 9 (9.4\%), facial puffiness/peripheral edema in 7 (7.3\%), nausea/vomiting/ diarrhea in $6(6.3 \%)$, and skin rash in $5(5.2 \%)$ patients. Grade 3-4 toxicity (myelosuppression) was seen in four (4.2\%) patients. Imatinib was stopped in three patients due to toxicities, one of whom progressed to BC; one patient was rechallenged with imatinib successfully and the other patient received nilotinib, due to imatinib intolerance.

\section{Second-Line TKI and Transplantation}

Nilotinib was administered to three patients, due to primary TKI resistance in two and imatinib intolerance (myelosuppression and rash) in one. Indications for dasatinib (two patients) were deranged liver enzymes while on nilotinib in one patient and loss of CCyR in the other. Twelve patients 
Table 3 Responses with imatinib treatment as per timelines

\begin{tabular}{|l|l|l|l|}
\hline Time since diagnosis & CHR (\%) & CCyR (\%) & MMR (\%) \\
\hline At 3 months & $57(60 \%)$ & & \\
\hline At 6 months & $+19(80 \%)$ & $14(14.7 \%)$ & $5(5.2 \%)$ \\
\hline At 12 months $^{\text {a }}$ & $+6(86 \%)$ & $19(34.7 \%)$ & $+13(18.8 \%)$ \\
\hline At 18 months $^{\text {a }}$ & $+2(88.4 \%)$ & $+8(43.1 \%)$ & $+08(27.3 \%)$ \\
\hline
\end{tabular}

Abbreviations: CCyR, complete cytogenetic response; CHR, complete hematological response; MMR, major molecular response.

aseven patients did not achieve CHR at 18 months (attained later).

were tested for IRMA, and three had T315I mutation. One patient with T315I mutation underwent allogeneic HSCT with a matched sibling donor (MSD) and the remaining patients died due to progressive CML.

Four patients underwent allogenic HSCT, indications being T315I mutation in one patient and CML-BC at diagnosis in three other patients. Two patients received HSCT from MSD and one each received a haploidentical transplant from father and matched unrelated donor. Of the four, two patients are alive and in CMR. One patient (BC at diagnosis) succumbed to progressive disease and the other (T315I mutation) due to chronic graft versus host disease after 2 years. Both these patients had received HSCT from MSD.

\section{Survival Analysis}

The median duration of follow-up for all patients was 98 months (range: 1-243 months). EFS and OS at 8 years for patients with CML-CP were $43.1 \%$ and $80.4 \%$ respectively (-Supplementary Figs. S1 and S2). On univariate analysis, attainment of CHR at 3 and 6 months, CCyR at 12 months, and $\mathrm{CP}$ was significantly associated with better OS (-Table 4). Attainment of CCyR at 6 and 12 months and MMR at 12 months was associated with significant EFS on univariate analysis ( - Table 4). On multivariate analysis, CP was associated with better OS $(p<0.001)$ and CCyR at 12 months was associated with better EFS $(p=0.04)$.

Poor compliance with treatment was observed in 19 (20\%) patients. To date, 64 of 95 patients are alive, 12 patients are lost to follow-up (all poorly compliant), and 19 patients have expired due to progressive CML.

\section{Discussion}

CML in children is rare. The majority of children with CML present with $\mathrm{CP}$ as was observed in our study where $88.4 \%$ of patients had CP at diagnosis. However, AP and BC accounted for 6.3 and $5.3 \%$ of cases respectively at diagnosis. In a report from Delhi, $3 \%$ and $17 \%$ of patients had a diagnosis of AP and $\mathrm{BC}$ respectively. ${ }^{20}$ Reports from developed countries indicate that 2-6\% of children present in AP and 2-4\% BC. ${ }^{6,21} \mathrm{CML}$ in children is different compared with adults ( $2 \%$ AP and $1 \%$ $\mathrm{BC})$, as a higher proportion present in $\mathrm{AP}$ and $\mathrm{BC} .^{22}$

Our findings were consistent with other studies in India, which report that CML is predominantly a disease of adolescents (-Table 5). Most studies report a median age of 13 years similar to our findings. ${ }^{5,23-28}$ We observed a male to female ratio of 1.3:1-this is similar to reports from southern India and considerably lesser than a higher male to female ratio reported by studies from northern and western India. ${ }^{20,23-28}$ The higher male to female ratio in CML observed in northwestern India could be due to social bias where females are not provided similar access to healthcare as males.

Response to treatment in our study is comparable to reports from other centers in India and developed countries. The 8-year EFS and OS for patients with CML-CP in our study were $43.1 \%$ and $80.4 \%$ respectively. This is the longest duration of follow-up and survival reported by any study in India. There is a $35 \%$ gap between EFS and OS in our study, which is comparable to the observation of a $28 \%$ gap in another report (5-year EFS and OS: $64 \%$ and $92 \%$ respectively). ${ }^{20}$ This gap highlights the fact that many patients with suboptimal responses to imatinib continue to respond for a prolonged time and the lower EFS is mostly due to noncompliance to treatment in our study. More recently, the availability of second-generation TKIs like nilotinib and dasatinib can be prescribed to those who fail imatinib.

Adult prognostic scoring systems like the Sokal, European Treatment and Outcome Study, and Hasford were not useful to predict outcome in pediatric patients with CML. ${ }^{2,29}$ This was also observed in our study where the SS was not prognostic of the outcome. Attaining CCyR at 12 months is an important landmark predicting superior outcomes in adult patients. ${ }^{14}$ Similarly, we also observed that the attainment of CCyR at 12 months was associated significantly with better EFS (8-year EFS: $69.1 \%$ vs $31.6 \% ; p=0.002$ ) and better OS (8-year OS: $96.8 \%$ vs $72.8 \% ; p=0.02$ ). Formal compliance was not assessed in our study as it was retrospective. However, it was documented in the case records that $20 \%$ of patients were noncompliant to treatment and $12 \%$ were lost to follow-up (includes patients who were noncompliant).

Animal studies, clinical cases, and prospective studies had shown deleterious effects of imatinib on growth kinetics and bone metabolism. ${ }^{30,31}$ Growth failure or retardation is an important and unique toxicity to be considered when using TKIs in the pediatric population. ${ }^{32}$ We do not have the data on serial growth monitoring as this study was retrospective.

Long-term follow-up of the stop imatinib study confirms that imatinib discontinuation is safe in adults. ${ }^{33}$ Pediatric studies on stopping imatinib in patients who are in CMR are ongoing. ${ }^{34}$ Future research in pediatric CML includes the safety, toxicity profile, long-term effects of second- and 
Pediatric CML Kesana et al. 565

Table 4 Univariate analysis of factors predicting the survival in the study population

\begin{tabular}{|c|c|c|c|c|}
\hline Parameter $(\mathrm{N})$ & 8-year EFS (\%) & $p$-Value & 8-year OS (\%) & $p$-Value \\
\hline Age & & \multirow[t]{3}{*}{0.17} & & \\
\hline$\leq 10$ years $(22)$ & 59.9 & & 90 & \multirow[t]{2}{*}{0.2} \\
\hline$>10$ years $(73)$ & 37.5 & & 96 & \\
\hline Sex & & \multirow[t]{3}{*}{0.93} & & \\
\hline Male (54) & 43.7 & & 80.3 & \multirow[t]{2}{*}{0.95} \\
\hline Female (41) & 41.5 & & 77.2 & \\
\hline Stage & & \multirow[t]{4}{*}{0.29} & & \multirow[t]{4}{*}{0.000} \\
\hline Chronic phase (84) & 43.1 & & 80.4 & \\
\hline Accelerated phase (6) & 33.3 & & 66.7 & \\
\hline Blast crisis (5) & 00 & & 00 & \\
\hline Splenomegaly & & \multirow[t]{3}{*}{0.99} & & \multirow[t]{3}{*}{0.77} \\
\hline$>10 \mathrm{~cm} \mathrm{(45)}$ & 41.0 & & 81 & \\
\hline $\begin{array}{l}<10 \mathrm{~cm}(45) \\
\text { Missing data (5) }\end{array}$ & 43.6 & & 77 & \\
\hline Hemoglobin $(\mathrm{g} / \mathrm{dL})$ & & \multirow[t]{3}{*}{0.37} & & \multirow[t]{3}{*}{0.79} \\
\hline$>10 \mathrm{gm} / \mathrm{dL}(34)$ & 57.2 & & 79.8 & \\
\hline$<10$ gm/dL (61) & 38.2 & & 78.3 & \\
\hline Total leucocyte count at presentation $\left(\times 10^{3}\right.$ cells $\left./ \mu \mathrm{L}\right)$ & & \multirow[t]{3}{*}{0.60} & & \multirow[t]{3}{*}{0.68} \\
\hline$<200(66)$ & 42.2 & & 84 & \\
\hline$>200(29)$ & 42.9 & & 73.4 & \\
\hline Platelet count ( $\times 10^{3}$ cells/uL) & & \multirow[t]{3}{*}{0.56} & & \multirow[t]{3}{*}{0.97} \\
\hline$<300(22)$ & 32 & & 79.7 & \\
\hline$>300(73)$ & 44.7 & & 77.6 & \\
\hline Sokal score & & \multirow[t]{4}{*}{0.36} & & \multirow[t]{4}{*}{0.68} \\
\hline Low risk (33) & 45.1 & & 86.3 & \\
\hline Intermediate risk (41) & 45.5 & & 72.3 & \\
\hline High risk (14) & 24.5 & & 77.9 & \\
\hline CHR at 3 months & & \multirow[t]{3}{*}{0.49} & & \multirow[t]{3}{*}{0.009} \\
\hline Yes (57) & 47.3 & & 90.6 & \\
\hline No (38) & 37.2 & & 69.5 & \\
\hline CHR at 6 months & & \multirow[t]{3}{*}{0.08} & & \multirow[t]{3}{*}{0.000} \\
\hline Yes (76) & 49.8 & & 90.3 & \\
\hline No (19) & 21.1 & & 44.9 & \\
\hline CCyR at 6 months & & \multirow[t]{3}{*}{0.03} & & \multirow[t]{3}{*}{0.19} \\
\hline Yes (14) & 79.5 & & 100 & \\
\hline No (81) & 38.5 & & 77.4 & \\
\hline CCyR at 12 months & & \multirow[t]{3}{*}{0.002} & & \multirow[t]{3}{*}{0.02} \\
\hline Yes (33) & 69.1 & & 96.8 & \\
\hline No (62) & 31.6 & & 72.8 & \\
\hline MMR at 12 months & & \multirow[t]{3}{*}{0.02} & & \multirow[t]{3}{*}{0.07} \\
\hline Yes (13) & 75.4 & & 100 & \\
\hline No (82) & 36.6 & & 75.8 & \\
\hline
\end{tabular}

Abbreviations: CCyR, complete cytogenetic response; CHR, complete hematological response; EFS, event-free survival; MMR, major molecular response; OS, overall survival. 
Pediatric CML Kesana et al.

\begin{tabular}{|c|c|c|c|c|c|c|c|c|c|}
\hline Еّ & 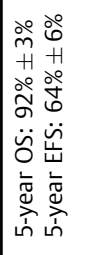 & $\Sigma$ & $\Sigma$ & 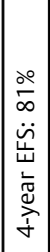 & 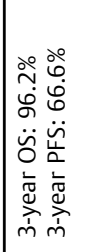 & 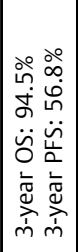 & 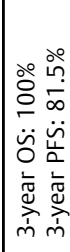 & 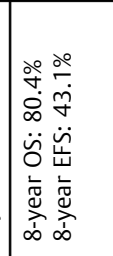 & 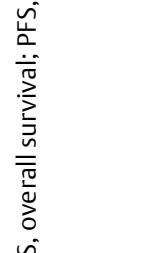 \\
\hline 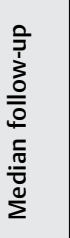 & 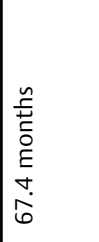 & $\Sigma$ & $\Sigma$ & $\Sigma$ & 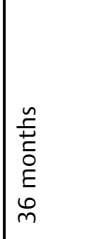 & $\mid \begin{array}{l}n \\
\\
ث \\
0 \\
E \\
E \\
0 \\
m\end{array}$ & 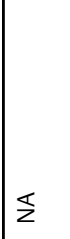 & 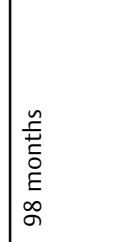 & 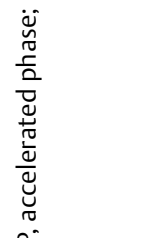 \\
\hline$\sum_{\Sigma}^{\infty}$ & 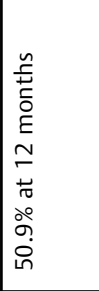 & z & z & $\Sigma$ & 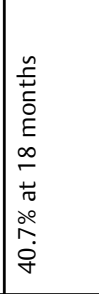 & 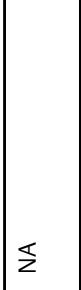 & 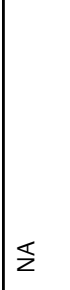 & 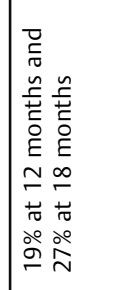 & 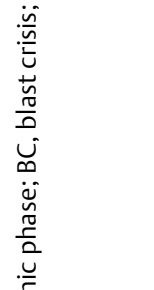 \\
\hline 总 & 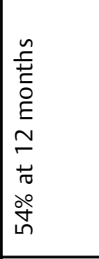 & 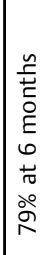 & z & 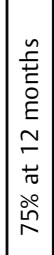 & 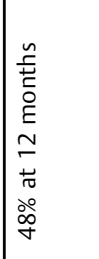 & \& & 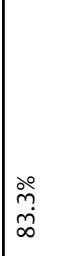 & 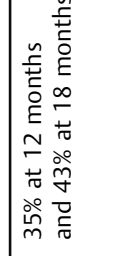 & 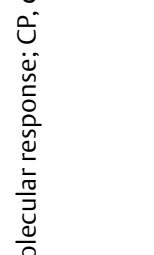 \\
\hline 号 & 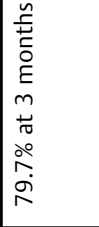 & 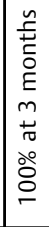 & 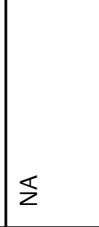 & 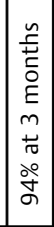 & 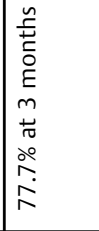 & z & ळे̊ & 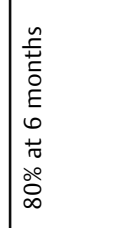 & 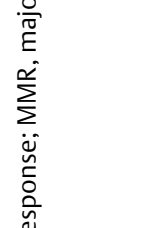 \\
\hline 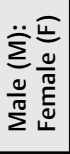 & $\begin{array}{r}\overline{\ddot{m}} \\
\end{array}$ & $\mid \begin{array}{c}\ddot{\ddot{o}} \\
\check{+}\end{array}$ & $\begin{array}{l}\overline{\dot{\omega}} \\
\dot{v}\end{array}$ & $\begin{array}{l}\ddot{\dot{g}} \\
\dot{\square}\end{array}$ & $\underset{\dot{m}}{\ddot{m}}$ & $\underset{\ddot{g}}{\ddot{g}}$ & $\begin{array}{l}\Delta \\
\hat{\Sigma}\end{array}$ & $\stackrel{\ddot{m}}{\longrightarrow}$ & 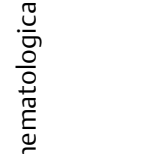 \\
\hline 遂 & 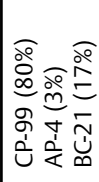 & ப் & 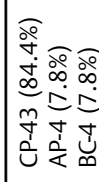 & ¿ & 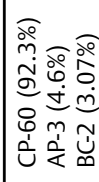 & ¿ & ¿ & 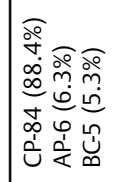 & 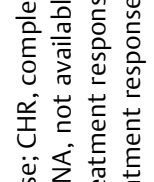 \\
\hline 总 & 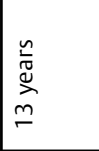 & 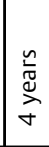 & \begin{tabular}{|l}
$n$ \\
$\stackrel{n}{0}$ \\
$\stackrel{2}{a}$ \\
$\sigma$
\end{tabular} & 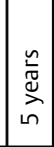 & 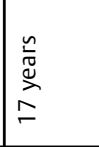 & 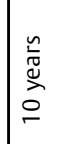 & \& & 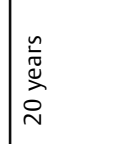 & 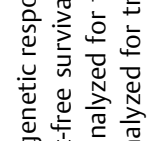 \\
\hline 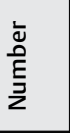 & $\stackrel{\sim}{\simeq}$ & $\stackrel{\infty}{+}$ & in & $\stackrel{\circ}{\circ}$ & ڤి & : & $\stackrel{m}{\text { s }}$ & nू & 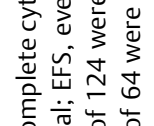 \\
\hline$\widehat{\vec{\Xi}}$ & 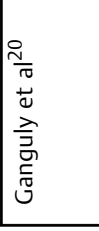 & 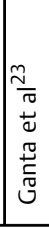 & 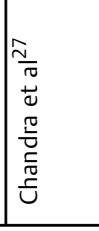 & 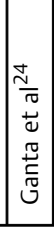 & 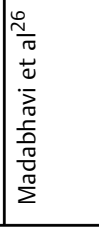 & 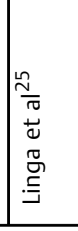 & 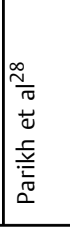 & 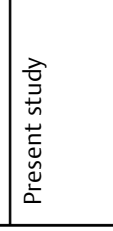 & 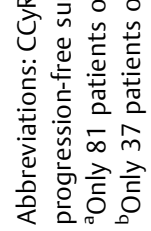 \\
\hline
\end{tabular}


third-generation TKIs, and discontinuation of TKIs. Successful discontinuation of the therapy in children with CML will reduce the long-term side effects associated with TKIs.

The role of HSCT in pediatric CML has reduced since the advent of TKIs. HSCT is currently performed in patients with CML BC or T315I mutation. ${ }^{34}$ Only 4 out of 95 patients in our cohort underwent HSCT.

Limitations of our study include the retrospective nature, availability of quantitative BCR-ABL PCR for response monitoring only from 2013, monitoring of BCR-ABL levels in patients on treatment being variable due to financial constraints, and nonavailability of data on growth kinetics.

\section{Conclusion}

Data on pediatric CML at our center are comparable to that of other Indian studies and western literature. Outcomes in pediatric CML are comparable to that of adults. Imatinib is well tolerated in children. The necessity of HSCT has drastically decreased after the introduction of TKIs.

\section{Availability of Data and Material}

The data regarding the findings of this study are available on request from the corresponding author.

\section{Author Contributions}

All coauthors have reviewed and contributed substantively and intellectually to the work described.

\section{Note}

Abstract on "A Retrospective Study of Pediatric Chronic Myeloid Leukemia" from 2000 to 2016 was presented in HAEMATOCON and PHOCON conferences in 2018, ICKSH2019.

\section{Funding \\ None.}

\section{Conflict of Interest}

No conflicts of interest or competing interest.

\section{Acknowledgments}

We would like to acknowledge our transplant coordinator, Ms. Vanita, for the help in coordinating and streamlining the transplant process.

\section{References}

1 Ries LAG, Smith MA, Gurney JG, et al. Cancer Incidence and Survival among Children and Adolescents: United States SEER Program 1975-1995, National Cancer Institute, SEER Program. NIH Pub. No. 99-4649. Bethesda, MD, 1999

2 Hijiya N, Schultz KR, Metzler M, Millot F, Suttorp M. Pediatric chronic myeloid leukemia is a unique disease that requires a different approach. Blood 2016;127(04):392-399

3 Dikshit RP, Nagrani R, Yeole B, Koyande S, Banawali S. Changing trends of chronic myeloid leukemia in greater Mumbai, India over a period of 30 years. Indian J Med Paediatr Oncol 2011;32(02): 96-100

4 Pushpam D, Bakhshi S. Paediatric chronic myeloid leukaemia: is it really a different disease? Indian J Med Res 2019;149(05): 600-609

5 Andolina JR, Neudorf SM, Corey SJ. How I treat childhood CML. Blood 2012;119(08):1821-1830

6 Suttorp M, Schulze P, Glauche I, et al. Front-line imatinib treatment in children and adolescents with chronic myeloid leukemia: results from a phase III trial. Leukemia 2018;32(07):1657-1669

7 Martinet D, Mühlematter D, Jotterand Bellomo M. [Fluorescent in-situ hybridization technique (FISH) in the diagnosis of Philadelphia translocation in chronic myeloid leukemia]. Schweiz Med Wochenschr 1996;126(20):855-863

8 Wells SJ, Phillips CN, Winton EF, Farhi DC. Reverse transcriptasepolymerase chain reaction for bcr/abl fusion in chronic myelogenous leukemia. Am J Clin Pathol 1996;105(06):756-760

9 Arber DA, Orazi A, Hasserjian R, et al. The 2016 revision to the World Health Organization classification of myeloid neoplasms and acute leukemia. Blood 2016;127(20):2391-2405

10 Millot F, Guilhot J, Nelken B, et al. Imatinib mesylate is effective in children with chronic myelogenous leukemia in late chronic and advanced phase and in relapse after stem cell transplantation. Leukemia 2006;20(02):187-192

11 Suttorp M, Millot F. Treatment of pediatric chronic myeloid leukemia in the year 2010: use of tyrosine kinase inhibitors and stem-cell transplantation. Hematology (Am Soc Hematol Educ Program) 2010;2010:368-376

12 Baccarani M, Saglio G, Goldman J, et al; European LeukemiaNet. Evolving concepts in the management of chronic myeloid leukemia: recommendations from an expert panel on behalf of the European LeukemiaNet. Blood 2006;108(06):1809-1820

13 Baccarani M, Cortes J, Pane F, et al; European LeukemiaNet. Chronic myeloid leukemia: an update of concepts and management recommendations of European LeukemiaNet. J Clin Oncol 2009;27(35):6041-6051

14 Baccarani M, Deininger MW, Rosti G, et al. European LeukemiaNet recommendations for the management of chronic myeloid leukemia: 2013. Blood 2013;122(06):872-884

15 Testoni N, Marzocchi G, Luatti S, et al. Chronic myeloid leukemia: a prospective comparison of interphase fluorescence in situ hybridization and chromosome banding analysis for the definition of complete cytogenetic response: a study of the GIMEMA CML WP. Blood 2009;114(24):4939-4943

16 Hughes T, Deininger M, Hochhaus A, et al. Monitoring CML patients responding to treatment with tyrosine kinase inhibitors: review and recommendations for harmonizing current methodology for detecting BCR-ABL transcripts and kinase domain mutations and for expressing results. Blood 2006;108 (01):28-37

17 Cross NCP, White HE, Müller MC, Saglio G, Hochhaus A. Standardized definitions of molecular response in chronic myeloid leukemia. Leukemia 2012;26(10):2172-2175

18 Müller MC, Cross NCP, Erben P, et al. Harmonization of molecular monitoring of CML therapy in Europe. Leukemia 2009;23(11): 1957-1963

19 Glivec ® International Patient Assistance Program (GIPAP). http://www.themaxfoundation.org/gipap/Default.aspx. Accessed December 8, 2021

20 Ganguly S, Pushpam D, Mian A, Chopra A, Gupta R, Bakhshi S. Real-world experience of imatinib in pediatric chronic phase chronic myeloid leukemia: a single-center experience from India. Clin Lymphoma Myeloma Leuk 2020;20(07):e437-e444

21 Millot F, Suttorp M, Guilhot J, et al. The International Registry for Chronic Myeloid Leukemia (CML) in Children and Adolescents (ICML-Ped-Study): objectives and preliminary results. Blood 2012; 120:3741 
22 Mitra D, Trask PC, Iyer S, Candrilli SD, Kaye JA. Patient characteristics and treatment patterns in chronic myeloid leukemia: evidence from a multi-country retrospective medical record chart review study. Int J Hematol 2012;95(03):263-273

23 Ganta RR, Nasaka S, Gundeti S. Impact of imatinib adherence on the cytogenetic response in pediatric chronic myeloid leukemia chronic phase. Indian J Pediatr 2016;83(09):1009-1012

24 Ganta RR, Nasaka S, Linga VG, Gundeti S, Maddali LS, Digumarti RR. Effectiveness of three prognostic scoring systems in predicting the response and outcome in pediatric chronic myeloid leukemia chronic phase on frontline imatinib. Indian $\mathrm{J}$ Med Paediatr Oncol 2017;38(03):282-286

25 Linga VG, Ganta RR, Kalpathi KI, et al. Response to imatinib mesylate in childhood chronic myeloid leukemia in chronic phase. South Asian J Cancer 2014;3(04):203-205

26 Madabhavi I, Patel A, Modi G, Anand A, Panchal H, Parikh S. Pediatric chronic myeloid leukemia: a single-center experience. J Cancer Res Ther 2020;16(01):110-115

27 Chandra D, Singh J, Deka R, et al. The biology of chronic myelogenous leukemia in childhood and young adolescents: an Indian perspective. Indian J Med Paediatr Oncol 2018;39:142-145

28 Parikh SK, Anand A, Panchal H, et al; Department of Medical and Pediatric Oncology, The Gujarat Cancer and Research Institute, Ahmedabad, Gujarat. INDIA. A retrospective study of clinical profile and long term outcome to imatinib mesylate alone in childhood chronic myeloid leukemia in chronic phase. Gulf J Oncolog 2017;1(23):15-20

29 Gurrea Salas D, Glauche I, Tauer JT, Thiede C, Suttorp M. Can prognostic scoring systems for chronic myeloid leukemia as established in adults be applied to pediatric patients? Ann Hematol 2015;94(08):1363-1371

30 Giona F, Mariani S, Gnessi L, et al. Bone metabolism, growth rate and pubertal development in children with chronic myeloid leukemia treated with imatinib during puberty. Haematologica 2013;98(03):e25-e27

31 Bansal D, Shava U, Varma N, Trehan A, Marwaha RK. Imatinib has adverse effect on growth in children with chronic myeloid leukemia. Pediatr Blood Cancer 2012;59(03):481-484

32 de la Fuente J, Baruchel A, Biondi A, et al; International BFM Group (iBFM) Study Group Chronic Myeloid Leukaemia Committee. Managing children with chronic myeloid leukaemia (CML): recommendations for the management of CML in children and young people up to the age of 18 years. Br J Haematol 2014;167(01): 33-47

33 Etienne G, Guilhot J, Rea D, et al. Long-term follow-up of the French Stop Imatinib (STIM1) Study in patients with chronic myeloid leukemia. J Clin Oncol 2017;35(03):298-305

34 Smeding C, Szydło A, Pieluszczak K, Grzeszkiewicz K, Pawelec K. Efficacy and safety of imatinib in paediatric CML - a single centre study. In Vivo 2019;33(03):869-875 